\title{
Differential co-expression analysis of a microarray gene expression profiles of pulmonary adenocarcinoma
}

\author{
SHIJIE FU, XUFENG PAN and WENTAO FANG \\ Department of Thoracic Surgery, Shanghai Chest Hospital, Shanghai Jiaotong University, Shanghai 200030, P.R. China
}

Received September 2, 2013; Accepted March 17, 2014

DOI: $10.3892 / \mathrm{mmr} .2014 .2300$

\begin{abstract}
Lung cancer severely reduces the quality of life worldwide and causes high socioeconomic burdens. However, key genes leading to the generation of pulmonary adenocarcinoma remain elusive despite intensive research efforts. The present study aimed to identify the potential associations between transcription factors (TFs) and differentially co-expressed genes (DCGs) in the regulation of transcription in pulmonary adenocarcinoma. Gene expression profiles of pulmonary adenocarcinoma were downloaded from the Gene Expression Omnibus, and gene expression was analyzed using a computational method. A total of 37,094 differentially co-expressed links (DCLs) and 251 DCGs were identified, which were significantly enriched in 10 pathways. The construction of the regulatory network and the analysis of the regulatory impact factors revealed eight crucial TFs in the regulatory network. These TFs regulated the expression of DCGs by promoting or inhibiting their expression. In addition, certain TFs and target genes associated with DCGs did not appear in the DCLs, which indicated that those TFs could be synergistic with other factors. This is likely to provide novel insights for research into pulmonary adenocarcinoma. In conclusion, the present study may enhance the understanding of disease mechanisms and lead to an improved diagnosis of lung cancer. However, further studies are required to confirm these observations.
\end{abstract}

\section{Introduction}

Globally, lung cancer is the leading cause of cancer mortality in males and the second leading cause of cancer mortality in females with $\sim 1.6$ million new lung cancer cases and 1.4 million mortalities expected to occur in one year (1). In China, the most frequently diagnosed cancer is lung cancer (2), and Chinese females have higher lung cancer rates than females in several European countries (3).

Correspondence to: Dr Wentao Fang, Department of Thoracic Surgery, Shanghai Chest Hospital, Shanghai Jiaotong University, No. 241 Huaihai East Road, Xuhui, Shanghai 200030, P.R. China E-mail: chest2013@126.com

Key words: pulmonary adenocarcinoma, differentially co-expressed genes, pathway
Almost $40 \%$ of lung cancer cases are adenocarcinoma, which usually originates in the peripheral lung tissue (4). Although several studies have assessed gene expression (5-7) or provided novel diagnostic aids (8) for pulmonary adenocarcinoma, key genes leading to the deterioration of pulmonary adenocarcinoma remain to be fully evaluated. Extensive efforts have been made to uncover the basic mechanisms underlying the initiation and progression of pulmonary adenocarcinoma, as well as to target these processes for diagnostics at molecular and genetic levels. Key genes and transcription factors (TFs) have an important role in the study of the disease. For example, the expression of the receptor of activated $\mathrm{C}$ kinase, which is an important 36-kDa cytosolic protein (9), was reported to be a useful biomarker for pulmonary adenocarcinoma (10). Furthermore, thyroid transcription factor-1 gene amplification has been discovered in certain types of lung adenocarcinoma, and this finding has been useful to inhibit transforming growth factor- $\beta$-mediated epithelial-to-mesenchymal transition in pulmonary adenocarcinoma cells (11). Compared with traditional research methods, DNA microarrays are one of the most popular technologies for studying the expression of genes at a large scale and ultimately associating them with diseases (12). The molecular mechanisms of pulmonary adenocarcinoma have yet to be fully understood, and a large-scale study of genes associated with this disease is necessary.

The aim of the present study was to explore the biochemical pathways leading to the deterioration of patients with pulmonary adenocarcinoma at the gene transcription level using a computational bioinformatics analysis of gene expression. Furthermore, the study aimed to identify the potential association between TFs and differentially co-expressed genes (DCGs) in the regulation of transcription. The present study may provide the groundwork to enable the exploration of the most variable genes leading to pulmonary adenocarcinoma.

\section{Materials and methods}

All patients provided informed consent prior to their inclusion in the present study, and all human studies were approved by the Ethics Committee of Shanghai Jiaotong University (Shanghai, China) and performed in accordance with the ethical standards.

Affymetrix microarray data and differential expression analysis. The gene expression profile of GSE 2514 (7) was downloaded from a public functional genomics data repository, 


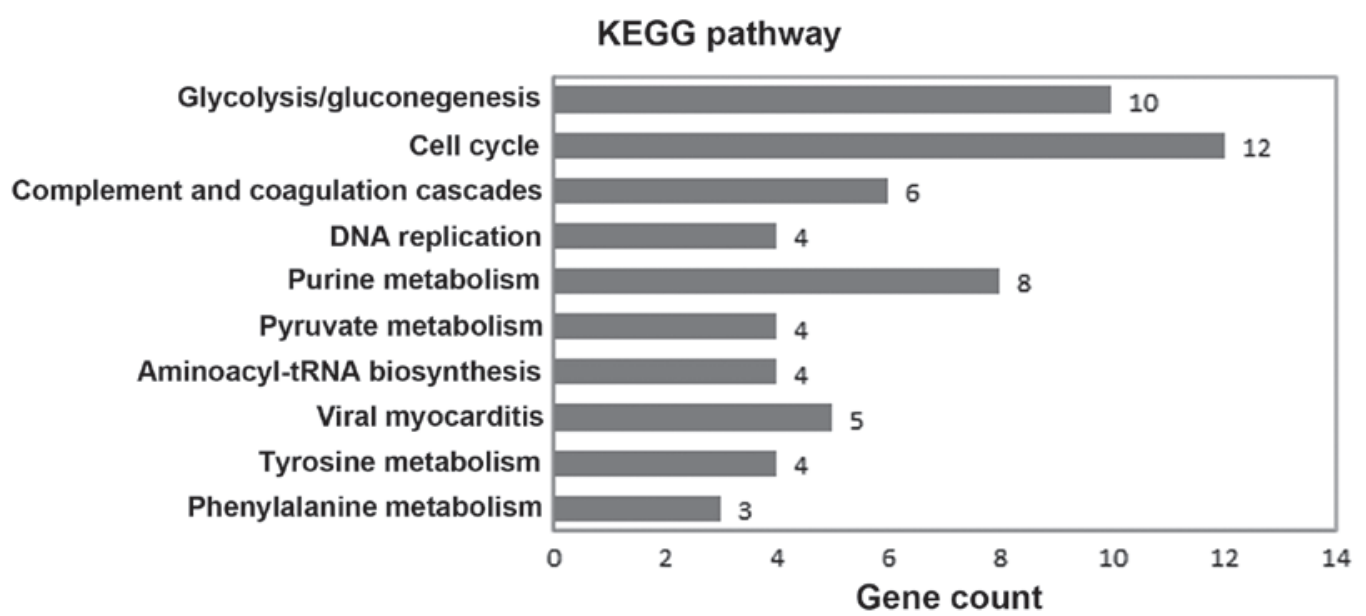

Figure 1. Significant metabolic pathways of differentially co-expressed genes: The abscissa represent the number of genes; the ordinate represents the name of the metabolic pathways. KEGG, Kyoto Encyclopedia of Genes and Genomes.

the Gene Expression Omnibus (GEO), which was based on the Affymetrix GPL8300 platform (Affymetrix Human Genome U95, Version 2 Array; Affymetrix, Inc., Santa Clara, CA, USA). These expression data were deposited by Stearman et al (7). A total of 39 samples, including 20 human lung cancer tissue samples and 19 human normal lung tissue samples, were analyzed with one replicate each.

The $\mathrm{R}$ package was used to analyze the gene expression profile (http://r-project.org/). The CEL source files were processed into expression estimates, and background correction and quartile data normalization were performed using the Robust Multi-array Average algorithm (13). The probability of genes being differentially expressed between pulmonary adenocarcinoma samples and normal samples was computed using the limma package (14). The t-test method was used to identify DEGs $(15,16)$. P-values $<0.05$ and $\mid \log F C l>0.5$ were considered to be statistically significant. The DCsum, DCp and DCe functions in the Differential Co-expression Analysis and Differential Regulation Analysis of Gene Expression Microarray Data (DCGL) $(17,18)$ (part of the R package) were used to evaluate DCGs and differentially co-expressed links (DCLs). A Q-value <0.05 was defined as the cut-off criterion.

Pathway enrichment analysis of DCGs. The Kyoto Encyclopedia of Genes and Genomes (KEGG) PATHWAY database is a comprehensive database containing various biochemical pathways (19). This database records networks of molecular interactions in cells, as well as variants of these networks specific to particular organisms. To explore the dysfunctional pathways in pulmonary adenocarcinoma samples, each group of genes was assessed using the Database for Annotation, Visualization and Integrated Discovery (DAVID) (20) for pathway enrichment analysis. The DAVID is a program that detects an enrichment of genes with specific gene ontology, KEGG and SwissProt terms.

Construction of a transcriptional regulatory network. TRANSFAC ${ }^{\circledR}(21)$ is a database of TFs, their genomic binding sites and DNA-binding profiles. TRANSFAC ${ }^{\circledR}$ comprises numerous data sheets, including SITE, GENE, FACTOR, CLASS, MATRIX, CELLS, METHOD and REFERENCE.
The association between downloaded human TFs and target genes in the database was analyzed. A total of 298 TFs and 6,495 TF-target pairs were selected. The DCLs were mapped to the TF-target pairs and the results were associated with the known target genes to obtain transcriptional regulation interrelations. Cytoscape (22) software was used for the construction of a transcriptional regulatory network.

\section{Results}

Differential gene expression in cancer tissue samples compared with normal samples. The gene expression profile of GSE 2514 was downloaded from the GEO database. Considering the scale of the calculations in the DCGL, pulmonary adenocarcinoma microarray data were analyzed and filtered using the limma and Affy packages to obtain the DEGs. A total of 1,379 DEGs were obtained with a $\mathrm{P}$-value $<0.05$ and $\mid \log \mathrm{FCl}>0.5$. The DCGL in the $\mathrm{R}$ package was used to screen DCLs and DCGs. When $\mathrm{Q}<0.05$ was used as the cut-off criterion, a total of 251 DCGs and 37,094 DCLs were obtained.

Identification of dysregulated pathways. In order to identify the dysregulated pathways in pulmonary adenocarcinoma samples, pathway enrichment analysis was performed using the online biological classification tool DAVID. A total of 10 pathways with a P-value $<0.1$ were enriched (Fig. 1 ). The most significant pathway was glycolysis/gluconeogenesis $\left(\mathrm{P}=5.49 \times 10^{-6}\right)$. The other significant pathways included the cell cycle $\left(\mathrm{P}=8.84 \times 10^{-5}\right)$, complement and coagulation cascades $(\mathrm{P}=0.018029)$ and $\mathrm{DNA}$ replication $(\mathrm{P}=0.044864)$. Ten significant pathways are listed in Table I.

TF regulatory network. All DCLs discovered in the present study were compared with the TRANSFAC database, and 10 TF-target gene pairs associated with pulmonary adenocarcinoma were observed, including eight TFs. The correlation difference (cor. diff.)-value (the sum of absolute values of the maximum absolute correlation for TF and target gene) indicated the degree of correlation between the TF and target gene (Table II). By mapping eight TFs to the TRANSFAC 
Table I. Pathway enrichment of differentially co-expressed genes in patients with cancer compared with normal controls with $\mathrm{P}<0.1$.

\begin{tabular}{|c|c|c|}
\hline Term & P-value & Differentially co-expressed genes \\
\hline Hsa00010: Glycolysis/gluconeogenesis & $5.49 \times 10^{-6}$ & $\begin{array}{l}A L D O A, G P I, T P I 1, P K M 2, A L D H 2, F B P 1, A D H 1 B, \\
A D H 1 A, P G K 1, G A P D H, P C K 1\end{array}$ \\
\hline Hsa04110: Cell cycle & $8.84 \times 10^{-5}$ & $\begin{array}{l}C C N B 1, C D C 6, C C N B 2, C C N D 2, B U B 1, P C N A, B U B 1 B \\
P R K D C, M C M 2, G A D D 45 B, M C M 4, M C M 6\end{array}$ \\
\hline Hsa04610: Complement and coagulation cascades & 0.018029 & VWF, C7, THBD, CD59, SERPING1, CFD \\
\hline Hsa03030: DNA replication & 0.044864 & PCNA, MCM2, MCM4, MCM6 \\
\hline Hsa00230: Purine metabolism & 0.052964 & $\begin{array}{l}\text { POLR2H, ITPA, PKM2, PDE4B, RRM1, NPR1, ENTPD6 } \\
\text { HPRT1 }\end{array}$ \\
\hline Hsa00620: Pyruvate metabolism & 0.058282 & $M E 1, P K M 2, A L D H 2, P C K 1$ \\
\hline Hsa00970: Aminoacyl-tRNA biosynthesis & 0.061901 & $T A R S, A A R S, E P R S, I A R S 2$ \\
\hline Hsa05416: Viral myocarditis & 0.072253 & LAMA2, ICAM1, CAV1, DMD, MYH11 \\
\hline Hsa00350: Tyrosine metabolism & 0.073368 & $G O T 2, M A O B, A D H 1 B, A D H 1 A, M I F$ \\
\hline Hsa00360: Phenylalanine metabolism & 0.084752 & $G O T 2, M A O B, M I F$ \\
\hline
\end{tabular}

Table II. Transcription regulation correlations in differentially co-expressed links.

\begin{tabular}{|c|c|c|c|c|}
\hline Transcription factor & Target gene & Cor. 1 & Cor. 2 & Cor. diff. \\
\hline FLI1 & CDKN1A & -0.593101612 & 0.701060623 & 1.294162235 \\
\hline ETS2 & $P L A U$ & $7.12 \times 10^{-1}$ & -0.513413211 & 1.225511357 \\
\hline HIF1A & $N R 4 A 1$ & 0.79000137 & -0.432670777 & 1.222672148 \\
\hline PPARG & $A T P 2 A 2$ & 0.448097377 & -0.721308657 & 1.169406033 \\
\hline LEF1 & VIM & 0.484138641 & -0.605684298 & 1.089822939 \\
\hline ETS2 & $J U N B$ & 0.735807964 & -0.337406532 & 1.073214496 \\
\hline ETV4 & VIM & 0.485632699 & -0.491208815 & 0.976841514 \\
\hline JUND & $P L A U$ & $6.27 \times 10^{-1}$ & 0.038142972 & 0.588792142 \\
\hline ETS2 & MMP9 & 0.619596343 & 0.05290016 & 0.566696183 \\
\hline VDR & CDKN1A & 0.497762462 & 0.034328193 & 0.463434268 \\
\hline
\end{tabular}

Cor. 1 and 2 represent the maximum absolute correlation of the transcription factor and the target gene. Cor. diff. represents the sum of the absolute value of correlations 1 and 2. FLI1, Fli-1 proto-oncogene, ETS transcription factor; ETS2, v-ets erythroblastosis virus E26 oncogene homolog 2; HIF1A, hypoxia-inducing factor $1 \alpha$; PPARG, peroxisome proliferator-activated receptor $\gamma$; LEF1, lymphoid enhancer-binding factor 1; ETV4, ets variant 4; JUND, jun D proto-oncogene; VDR, vitamin D receptor; CDKN1A, cyclin-dependent kinase inhibitor 1A; $P L A U$, plasminogen activator, urokinase; NR4A1, nuclear receptor subfamily 4, group A, member 1; ATP2A2, ATPase, Ca ${ }^{++}$transporting, cardiac muscle, slow twitch 2; VIM, vimentin; JUNB, jun B proto-oncogene; MMP9, matrix metallopeptidase 9; Cor. 1, correlation 1; Cor. 2, correlation 2; Cor. diff., correlation difference.

database again, 366 regulation associations that were linked with those TFs were obtained. By processing these associations with Cytoscape software, eight TFs and 308 target genes were identified in the transcriptional regulatory network. Furthermore, several TFs and target genes belonging to DCGs did not appear among the DCLs in the present study, which indicated that those TFs may be synergistic with other factors. The results are illustrated in Fig. 2.

\section{Discussion}

The present study investigated gene expression profiles in patients with lung cancer and healthy controls to explore the biochemical pathways leading to the deterioration associated with pulmonary adenocarcinoma at the gene transcription level using a computational bioinformatics method. Furthermore, the study identified the most variable genes leading to pulmonary adenocarcinoma according to the associations between TFs and target genes. A total of 251 DCGs and 37,094 DCLs were obtained following DCGL analysis. These 251 DCGs were significantly enriched in 10 pathways. In addition, certain DCGs belonging to TF-target pairs did not appear among the DCLs. These TF-target gene pairs may have a synergistic effect with other TFs, which may provide novel insights for research into pulmonary adenocarcinoma.

In the present study, KEGG PATHWAY analysis was used to identify the dysregulated pathways in pulmonary adenocarcinoma samples; 10 pathways, including glycolysis/gluconeogenesis, the cell cycle and the complement and coagulation cascades, were highlighted. These pathways 


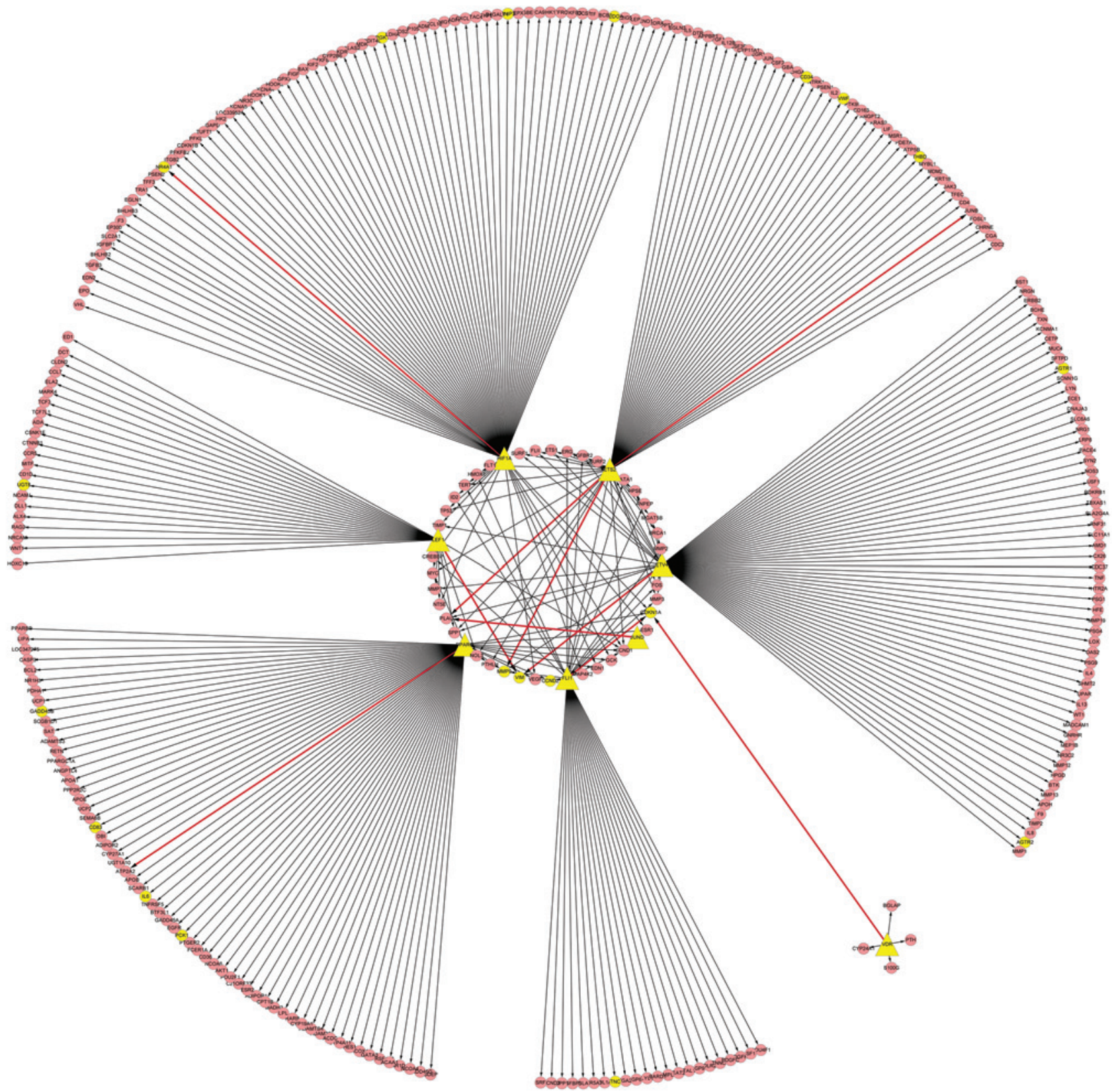

Figure 2. Transcriptional regulation network: Triangles in the figure represent TFs; circles represent the target genes; yellow dots represent DCGs; pink dots represent non-DCGs; red lines represent 10 correlations; black lines represent correlations of TF-target regulation. DCG, differentially co-expressed gene; TF, transcription factor.

were associated with energy conversion, cell replication and the immune response. The most significant pathway was glycolysis/gluconeogenesis. Glycolysis involves the conversion of glucose into pyruvate and the generation of small amounts of adenosine triphosphate and nicotinamide adenine dinucleotide, and gluconeogenesis is a pathway leading to the synthesis of glucose from noncarbohydrate precursors. Gluconeogenesis is the reverse of glycolysis, but involves minor variations or alternative paths. A series of DCGs were included in the glycolysis/gluconeogenesis pathway, including phosphoglycerate kinase $1(P G K 1)$. Chen et al (23) suggested that four proteins, including the protein encoded by $P G K 1$, that are involved in the glycolysis pathway are overexpressed in pulmonary adenocarcinoma; this overexpression was suggested to be associated with low survival rates in patients with pulmonary adenocarcinoma. A study on breast cancer demonstrated that tumors had abnormal bioenergetics, and patients with cancer showed a systematic loss of energy involving the interaction of tumor glycolysis and gluconeogenesis (24). The results of the differential co-expression analysis in the present study are in accordance with previous studies and indicated that the genes in the glycolysis/gluconeogenesis pathway have an important role in the development and progression of pulmonary adenocarcinoma.

A transcriptional regulatory network with 308 target genes and eight TFs was obtained using Cytoscape software. In this network, 19 target genes and all of the eight TFs [Fli-1 proto-oncogene, ETS transcription factor (FLI1), v-ets erythroblastosis 
virus E26 oncogene homolog 2 (ETS2), hypoxia-inducible factor $1 \alpha$ (HIF1A), peroxisome proliferator-activated receptor $\gamma$ (PPARG), lymphoid enhancer-binding factor 1 (LEF1), ets variant 4 (ETV4), jun D proto-oncogene (JUND) and vitamin D receptor (VDR)] were DCGs. The most significant correlation of TF-target gene pairs was FLI1-cyclin-dependent kinase inhibitor 1A (CDKN1A) with a cor. diff.-value of 1.294162235. Other significant correlations included ETS2-urokinase-type plasminogen activator (PLAU) (cor. diff.-value, 1.225511357) and HIF1A-nuclear receptor subfamily 4, group A, member 1 (NR4A1) (cor. diff.-value, 1.222672148). Correlations of TF-target genes are listed in Table II.

FLI1 is a member of the ETS family of TFs characterized by the presence of the evolutionary conserved DNA-binding (ETS) domain, which recognizes the purine-rich GGA (A/T) core sequence (25). Sankar et al (26) suggested that the EWS RNA-binding protein 1 gene fuses with FLI1 to produce the EWS/FLI fusion protein, which is the abnormal TF that drives tumor development in Ewing sarcoma. CDKN1A is a type of CDK inhibitor (CKI), and is a cell cycle inhibitor gene regulated by VDR. The expression or stability of CKIs is reduced in tumors and leads to organ hyperplasia and increased tumor susceptibility (27). CDKNIA plays essential roles in the DNA damage response by inducing cell cycle arrest and directly inhibiting DNA replication, as well as by regulating fundamental processes, including apoptosis and transcription (28). The deletion of CDKN1A improves stem cell function and increases the lifespan of mice with dysfunctional telomeres without accelerating cancer formation (29). To date, genes whose expression has been reported to be repressed by EWS/FLI include CDKN1A (30,31).

It was also observed in the present study that DNA-binding transcription factors have three target genes. The expression of ETS2 has been shown to be elevated in certain cancer tissue samples and have a significant role in cancer progression (32). The genes regulated by ETS 2 are those encoding enzymes that degrade the extracellular matrix, including stromelysin and collagen (33). The most significant relevant target gene to ETS2 is $P L A U$, which is currently used as a diagnostic marker (34). $P L A U$ is closely correlated with the expression of a series of genes in lung cancer cell lines (35). However, in renal cancer cells, PLAU showed cancer cell-specific methylation that did not correlate well with expression status (36) and it was not specifically associated with colon cancer (37). The results of the cotransfection of the PLAU enhancer-CAT construct in the presence of increasing amounts of the ETS2- $\beta$-galactosidase expression vector showed that the co-expression of the ETS dominant-negative protein resulted in the almost complete inhibition of the PLAU enhancer induction (38). The second relevant gene to ETS2 is $J U N B$, which represents an important target in diseases associated with cancer and fibrosis (39). The expression of $J U N B$ is inactivated by methylation in chronic myeloid leukemia (40). The third relevant gene to ETS2 is matrix metalloproteinase-9 (MMP9). The expression of $M M P 9$ in non-small cell lung cancer contributes to tumor cell invasiveness (41). ETS can regulate MMPs, and MMP9 expression was shown to be suppressed by ETS blockage through overexpression of a dominant-negative form of ETS1 (42).

HIFlA encodes a pivotal TF that regulates angiogenesis by inducing the expression of vascular endothelial growth factor, interleukin-8 and a basic fibroblast growth factor (43). HIF1A is considered to be one of the key regulators of tumor angiogenesis. NR4Al is the target gene of HIF1A. NR4Al was demonstrated to reduce the migration of normal and breast cancer cell lines (44). Results regarding the knockdown or overexpression of NR4Al in lung cancer cells suggest that this receptor exhibits pro-oncogenic activity and enhances cell survival and/or proliferation (45).

The other TFs examined in the present study showed less correlation with their target genes, but these also had an important role in the molecular mechanism of the disease. PPARG is a member of the PPAR family, which has a pivotal role in adipogenesis and glucose homeostasis (46). LEF1 mRNA levels are important statistical metrics in cancer. A study on ovarian, fallopian tube and peritoneal cancer indicated that LEF1 overexpression may be predictive of poor overall survival (47). Furthermore, ETV4 was demonstrated to be a useful marker in study on prostate cancer (48), and JUND and its target gene PLAU were shown to have an important role in gene expression in cancer cells (49). The TF with the least correlation was VDR, which only had five target genes on the map. This indicates that VDR is an important site for carcinogenesisP.

In conclusion, a total of 10 pathways were enriched in pulmonary adenocarcinoma tissue samples, and the most significant pathway of DCGs in the present study was glycolysis/gluconeogenesis. Ten TF-target gene pairs that were associated with pulmonary adenocarcinoma were discovered in the transcriptional regulatory network. Co-expression analysis of these TFs and target genes may provide novel ideas for cancer research, and the results of the present study may provide groundwork enabling the investigation of the most variable genes leading to the development and progression of pulmonary adenocarcinoma. However, further experiments are required to confirm these observations.

\section{References}

1. Ferlay J, Shin HR, Bray F, Forman D, Mathers C and Parkin DM: Estimates of worldwide burden of cancer in 2008: GLOBOCAN 2008. Int J Cancer 127: 2893-2917, 2010.

2. Jemal A, Center MM, DeSantis C and Ward EM: Global patterns of cancer incidence and mortality rates and trends. Cancer Epidemiol Biomarkers Prev 19: 1893-1907, 2010.

3. Mackay J, Eriksen M and Shafey O (eds): The Tobacco Atlas. 2nd edition, American Cancer Society, Atlanta, GA, 2006.

4. Hong WK, Bast RC, Hait WN, Kufe DW, Pollock RE, Weichselbaum RR, Holland HF and Frei E III (eds): Cancer Medicine. 8th edition, PMPH, New York, NY, 2010.

5. Garber ME, Troyanskaya OG, Schluens K, Petersen S, Thaesler Z, Pacyna-Gengelbach M, van de Rijn M, Rosen GD, Perou CM, Whyte RI, et al: Diversity of gene expression in adenocarcinoma of the lung. Proc Natl Acad Sci USA 98: 13784-13789, 2001.

6. Director's Challenge Consortium for the Molecular Classification of Lung Adenocarcinoma; Shedden K, Taylor JM, Enkemann SA, Tsao MS, Yeatman TJ, Gerald WL, Eschrich S, Jurisica I, Giordano TJ, Misek DE, et al: Gene expression-based survival prediction in lung adenocarcinoma: a multi-site, blinded validation study. Nat Med 2008; 14: 822-827.

7. Stearman RS, Dwyer-Nield L, Zerbe L, Blaine SA, Chan Z, Bunn PA Jr, Johnson GL, Hirsch FR, Merrick DT, Franklin WA, et al: Analysis of orthologous gene expression between human pulmonary adenocarcinoma and a carcinogen-induced murine model. Am J Pathol 167: 1763-1775, 2005.

8. Jiang H, Deng Y, Chen HS, Tao L, Sha Q, Chen J, Tsai CJ and Zhang S: Joint analysis of two microarray gene-expression data sets to select lung adenocarcinoma marker genes. BMC Bioinformatics 5: 81, 2004. 
9. Ron D, Chen $\mathrm{CH}$, Caldwell J, Jamieson L, Orr E and Mochly-Rosen D: Cloning of an intracellular receptor for protein kinase C: a homolog of the beta subunit of G proteins. Proc Natl Acad Sci USA 91: 839-843, 1994.

10. Nagashio R, Sato Y, Matsumoto T, Kageyama T, Satoh Y, Shinichiro R, Masuda N, Goshima N, Jiang SX and Okayasu I: Expression of RACK1 is a novel biomarker in pulmonary adenocarcinomas. Lung Cancer 69: 54-59, 2010.

11. Saito RA, Watabe T, Horiguchi K, Kohyama T, Saitoh M, Nagase T and Miyazono K: Thyroid transcription factor-1 inhibits transforming growth factor- $\beta$-mediated epithelial-to-mesenchymal transition in lung adenocarcinoma cells. Cancer Res 69: 2783-2791, 2009.

12. Fang G, Kuang R, Pandey G, Steinbach M, Myers CL and Kumar V: Subspace differential coexpression analysis: problem definition and a general approach. Pac Symp Biocomput: $145-156,2010$

13. Irizarry RA, Hobbs B, Collin F, Beazer-Barclay YD, Antonellis KJ, Scherf U and Speed TP: Exploration, normalization, and summaries of high density oligonucleotide array probe level data. Biostatistics 4: 249-264, 2003.

14. Diboun I, Wernisch L, Orengo CA and Koltzenburg M. Microarray analysis after RNA amplification can detect pronounced differences in gene expression using limma. BMC Genomics 7: 252, 2006

15. Lee HK, Hsu AK, Sajdak J, Qin J and Pavlidis P. Coexpression analysis of human genes across many microarray data sets. Genome Res 14: 1085-1094, 2004.

16. Stuart JM, Segal E, Koller D and Kim SK: A gene-coexpression network for global discovery of conserved genetic modules. Science 302: 249-255, 2003.

17. Liu BH, Yu H, Tu K, Li C, Li YX and Li YY: DCGL: an R package for identifying differentially coexpressed genes and links from gene expression microarray data. Bioinformatics 26 : 2637-2638, 2010.

18. Yu H, Liu BH, Ye ZQ, Li C, Li YX and Li YY: Link-based quantitative methods to identify differentially coexpressed genes and gene pairs. BMC Bioinformatics 12: 315, 2011.

19. Kanehisa M and Goto S: KEGG: kyoto encyclopedia of genes and genomes. Nucleic Acids Res 28: 27-30, 2000.

20. Huang da W, Sherman BT, Tan Q, Collins JR, Alvord G, Roayaei J, Stephens R, Baseler MW, Lane HC and Lempicki RA. The DAVID Gene Functional Classification Tool: a novel biological module-centric algorithm to functionally analyze large gene lists. Genome Biol 8: R183, 2007.

21. Wingender E, Chen X, Hehl R, Karas H, Liebich I, Matys V, Meinhardt T, Prüss M, Reuter I and Schacherer F: TRANSFAC: an integrated system for gene expression regulation. Nucleic Acids Res 28: 316-319, 2000

22. Smoot ME, Ono K, Ruscheinski J, Wang PL and Ideker T: Cytoscape 2.8: new features for data integration and network visualization. Bioinformatics 27: 431-432, 2011.

23. Chen G, Gharib TG, Wang H, Huang CC, Kuick R, Thomas DG, Shedden KA, Misek DE, Taylor JM, Giordano TJ, et al: Protein profiles associated with survival in lung adenocarcinoma. Proc Natl Acad Sci USA 100: 13537-13542, 2003.

24. Perumal SS, Shanthi P and Sachdanandam P. Therapeutic effect of tamoxifen and energy-modulating vitamins on carbohydrate-metabolizing enzymes in breast cancer. Cancer Chemother Pharmacol 56: 105-114, 2005.

25. Oikawa T and Yamada T. Molecular biology of the Ets family of transcription factors. Gene 303: 11-34, 2003.

26. Sankar S, Gomez NC, Bell R, Patel M, Davis IJ, Lessnick SL and Luo W. EWS and RE1-silencing transcription factor inhibit neuronal phenotype development and oncogenic transformation in Ewing sarcoma. Genes Cancer 4: 213-223, 2013.

27. Lüdtke TH, Farin HF, Rudat C, Schuster-Gossler K, Petry M, Barnett P, Christoffels VM and Kispert A. Tbx2 controls lung growth by direct repression of the cell cycle inhibitor genes Cdkn1a and Cdkn1b. PLoS Genet 9: e1003189, 2013

28. Cazzalini O, Scovassi AI, Savio M, Stivala LA and Prosperi E. Multiple roles of the cell cycle inhibitor p21(CDKN1A) in the DNA damage response. Mutat Res 704: 12-20, 2010.

29. Choudhury AR, Ju Z, Djojosubroto MW, Schienke A, Lechel A, Schaetzlein S, Jiang H, Stepczynska A, Wang C, Buer J, et al: Cdknla deletion improves stem cell function and lifespan of mice with dysfunctional telomeres without accelerating cancer formation. Nat Genet 39: 99-105, 2007.
30. Schwentner R: Molecular mechanisms of transcriptional repression by the EWS-FLI1 oncogene in Ewing's sarcoma. PhD dissertation, University of Vienna. Publication no. AC07884381, 2008.

31. Riggi N, Cironi L, Provero $\mathrm{P}$, Suvà $\mathrm{ML}$, Kaloulis $\mathrm{K}$, Garcia-Echeverria C, Hoffmann F, Trumpp A and Stamenkovic I: Development of Ewing's sarcoma from primary bone marrow-derived mesenchymal progenitor cells. Cancer Res 65: 11459-11468, 2005

32. Liu AY, Corey E, Vessella RL, Lange PH, True LD, Huang GM, Nelson PS and Hood L: Identification of differentially expressed prostate genes: increased expression of transcription factor ETS-2 in prostate cancer. Prostate 30: 145-153, 1997.

33. Butticé $\mathrm{G}$ and Kurkinen M: Oncogenes control stromelysin and collagenase gene expression. Contrib Nephrol 107: 101-107, 1994.

34. Sudol M: From Rous sarcoma virus to plasminogen activator, src oncogene and cancer management. Oncogene 30: 3003-3010, 2011.

35. Watanabe T, Miura T, Degawa Y, Fujita Y, Inoue M, Kawaguchi M and Furihata C: Comparison of lung cancer cell lines representing four histopathological subtypes with gene expression profiling using quantitative real-time PCR. Cancer Cell Int 10: 2, 2010.

36. Ibanez de Caceres I, Dulaimi E, Hoffman AM, Al-Saleem T, Uzzo RG and Cairns P: Identification of novel target genes by an epigenetic reactivation screen of renal cancer. Cancer Res 66: 5021-5028, 2006

37. Maness L, Goktepe I, Chen H, Ahmedna M and Sang S: Impact of Phytolacca americana extracts on gene expression of colon cancer cells. Phytother Res: Apr 4, 2013 (Epub ahead of print) doi: $10.1002 /$ ptr.4979

38. Cirillo G, Casalino L, Vallone D, Caracciolo A, De Cesare D and Verde P: Role of distinct mitogen-activated protein kinase pathways and cooperation between Ets-2, ATF-2, and Jun family members in human urokinase-type plasminogen activator gene induction by interleukin-1 and tetradecanoyl phorbol acetate. Mol Cell Biol 19: 6240-6252, 1999.

39. Gervasi M, Bianchi-Smiraglia A, Cummings M, Zheng Q, Wang D, Liu S and Bakin AV: JunB contributes to Id 2 repression and the epithelial-mesenchymal transition in response to transforming growth factor- $\beta$. J Cell Biol 196: 589-603, 2012.

40. Yang MY, Liu TC, Chang JG, Lin PM and Lin SF: JunB gene expression is inactivated by methylation in chronic myeloid leukemia. Blood 101: 3205-3211, 2003.

41. Liu PL, Tsai JR, Hwang JJ, Chou SH, Cheng YJ, Lin FY, Chen YL, Hung CY, Chen WC, Chen YH and Chong IW: High-mobility group box 1-mediated matrix metalloproteinase-9 expression in non-small cell lung cancer contributes to tumor cell invasiveness. Am J Resp Cell Mol Biol 43: 530-538, 2010.

42. Sahin A, Vercamer C, Kaminski A, Fuchs T, Florin A, Hahne JC, Mattot V, Pourtier-Manzanedo A, Pietsch T, Fafeur V and Wernert $\mathrm{N}$ : Dominant-negative inhibition of Ets 1 suppresses tumor growth, invasion and migration in rat C6 glioma cells and reveals differentially expressed Ets 1 target genes. Int J Oncol 34: 377 , 2009.

43. Cha ST, Chen PS, Johansson G, Chu CY, Wang MY, Jeng YM, Yu SL, Chen JS, Chang KJ, Jee SH, et al: MicroRNA-519c suppresses hypoxia-inducible factor-1 alpha expression and tumor angiogenesis. Cancer Res 70: 2675-2685, 2010.

44. Alexopoulou AN, Leao M, Caballero OL, Da Silva L, Reid L, Lakhani SR, Simpson AJ, Marshall JF, Neville AM and Jat PS: Dissecting the transcriptional networks underlying breast cancer: NR4A1 reduces the migration of normal and breast cancer cell lines. Breast Cancer Res 12: R51, 2010.

45. Lee SO, Li X, Khan S and Safe S: Targeting NR4A1 (TR3) in cancer cells and tumors. Expert Opin Ther Targets 15: 195-206, 2011.

46. Robbins GT and Nie D: PPARgamma, bioactive lipids, and cancer progression. Front Biosci (Landmark Ed) 17: 1816-1834, 2012

47. Clements A, Engle D, Shelton D, Neff T, Park S, Bender D, Ahmed A, De Geest K, Button A, Engelhardt JF and Goodheart M: Lymphoid Enhancing Factor 1 (Lef-1) overexpression in epithelial ovarian, fallopian tube and peritoneal cancer and associations with clinical factors. Proc Obstet Gynecol 2: 1-2, 2011.

48. Tomlins SA, Mehra R, Rhodes DR, Smith LR, Roulston D, Helgeson BE, Cao X, Wei JT, Rubin MA, Shah RB and Chinnaiyan AM: TMPRSS2: ETV4 gene fusions define a third molecular subtype of prostate cancer. Cancer Res 66: 3396-3400, 2006.

49. Darnell JE Jr: Transcription factors as targets for cancer therapy. Nat Rev Cancer 2: 740-749, 2002 